\title{
Enhancing Thai undergraduates' ability on scholarly English presentation: Miller's model-based instruction
}

\author{
Thassanant Unnanantn*
}

Faculty of Education, Suan Sunandha Rajabhat University, Bangkok, Thailand

\author{
Key Words \\ Thai undergraduates \\ Pre-service teachers \\ Scholarly English presentation \\ Miller's model \\ Instruction
}

Received: 13 October 2016

Accepted: 27 February 2017

Published: 21 April 2017

\begin{abstract}
This study attempted to strengthen pre-service English major teachers' academic English presentation ability through the instruction based on Miller's model and investigate their attitudes towards the teaching methodology. The cluster sampling was used in this study. Therefore, 26 pre-service teachers studying in the English major program were selected. The research instruments for the development were 1) a course syllabus whose instructional process was systematized according to Miller's model, 2) scholarly presentation knowledge and language tests, 3) assessment forms for both simulated and authentic presentation contexts, and 4) an attitude investigation form. Regarding the instructional stages of Miller's model: Knows, Knows how, Shows how and Does, the sampling group's range of score was classified into the lowest and the highest with their degrees of development as follows: 60\% (average) and $90 \%$ (very good) for Knows, $70 \%$ (good) and $90 \%$ (very good) for Knows how, $60 \%$ (average) and $100 \%$ (very good) for Shows how and $72 \%$ (good) and $100 \%$ (very good) for Does. For their mean score of progress, 16 and 10 students scored in the very good and good levels. From the attitude investigation by open-ended questions, the results unfolded their positive attitudes towards the teaching methodology, which helped them learn, the learning atmosphere, and the teacher. The results indicate that the instruction model composed of cognitive and behavioral teaching steps is of great assistance for teachers to understand individual students' learning problems and academic needs. Furthermore, the use of this model can help them gain a good command of skills together with endurable understanding and prepare them to perform effectively and wisely in their careers and real world situations.
\end{abstract}

(C)2017 The Author. Published by TAF Publishing.

\section{INTRODUCTION}

In the age of advancement in technology and communication where global citizens have easier access to information and knowledge, a good command of English skills and language knowledge are a good contribution to effectiveness in the search and use of abundant information for several purposes, for instance, academic development, world update, and general communication. Therefore, effective skills with solid knowledge of English can be a good support for greater success in careers and education and make cross cultural communication in a multi-cultural context go smoothly. In Thai society, English is highly admired as a language used among the educated so those who possess both accuracy and fluency in English communication are always highly valued with the image of graduating with a good degree, having rich support from their knowledgeable families, possessing a high status occupation or position and being highly qualified. Of all the communicative English skills, Angwatanakul (1994) and Tantrakul (2014) proposed that the speaking skill is

\footnotetext{
${ }^{*}$ Corresponding author: Thassanant Unnanantn

†Email: thassanant.un@ssru.ac.th
} 
the most important as it is a tool for expressing ideas, sharing knowledge, news and other information and keeping contact with people.

Nevertheless, among a large number of Thai people having studied English for a long time, there are still many facing several problems while speaking English in both informal situations requiring spontaneous speech for simple conversations and formal contexts where organized content needs to be passed on in an appropriate language level (Abdul Amir, 2015; Oradee, 2012; Taher et al., 2016). Therefore, their limited speaking skill can cause them hesitation and diffidence while communicating. That is, they probably take too much time thinking about words to use, grammar, and a comparison of their mother tongue to the target language before producing speech to respond to a simple conversation and every time they are to speak in English, it seems like doing a language task needing much endeavor.

Beyond speaking in general situations, the scholarly presentation ability is more complicated and requires more understandings and practices in several components because it is speaking controlled by verbal and visual information arrangement, cross-cultural concern, and an appropriate delivery style Alvesson, Duarte, Gupta and Govindarajan, Holden, Leonard and Sensiper (cited in Sukitkanaporn and Supakorn, 2014). Also, manners and the manipulation facilities are part of effective presentation. However, from the study by Sukitkanaporn and Supakorn (2014), they unveiled that many still faced problems in their presentations and the results they discovered from their graduate students were delivery and content organization. In addition to their students, they also found many presenters in a conference made unclear opening, read through the slides and made their slides too dense with texts.

For pre-service teachers majoring in English, the expectation from society is very high because it is expected that being a teacher of English means they are to use English excellently and express knowledge effectively. In contrast, if their achievement is lower than the society's expectation, the quality of English instruction for the next generation will be questionable and cause a serious risk for their students to acquire wrong knowledge. Consequently, educators and researchers in this discipline have been attempting to develop teaching techniques, materials, and related innovation to improve Thai people's English skills.

From a wide range of instructional methodologies used in skill and knowledge application development, Miller's model is an instructional procedural structure which makes learning activities more meaningful for students. The procedural stages of this model start from 1) Knows: giving knowledge 2) Knows how: examining the students' knowledge or having them express the knowledge, theories or principles they have learnt 3) Shows how: assigning them to demonstrate or do some task with the use of their learnt knowledge or skill in a controlled environment and 4) Does: giving them some opportunity to use the knowledge or perform a skill in an authentic atmosphere. Also, formative assessment is included in each stage to assess their quality in terms of effectiveness and efficiency (Allery, 2009; Al-Wardy, 2010; Boursicot et al., 2011; Miller, 1990; Norcini, 2003; Ramani and Sam, 2008; Rethans et al., 2002).

From the model's structure, it is a sequential combination between cognition level learning (Knows and Knows how) and competence and performance levels (Shows how and Does). Through all these layers, students can have endurable knowledge and understand in what extent their skill or knowledge they have been taught is practical because the performance in the ultimate stage of this model, Does, will give them a direct experience. In addition, within this model, an instructor can better understand their difficulties 
through formative assessment at each step and then, solve their learning problems immediately for the reason of not allowing any shortcomings to happen repeatedly and become fossilized. To work on the model with its full performance, the instruction needs to be made strictly continuous along the string of this model and skipping any stage makes it invalid (Boonphadung and Thassanant, 2015; Boursicot et al., 2011; Miller, 1990; Rethans et al., 2002).

From the reasons and principles above, the researcher realized the importance of the English presentation ability in an academic atmosphere and had an aim to develop it with Miller's model. The attitudes towards the pedagogy were also surveyed to consider the instruction's effectiveness and efficiency other than score results. Hence, a questionnaire with open-ended questions was designed to collect the information so as to make the students feel free to show their thoughts (Foddy, 1993). The questions in the questionnaire were in 4 dimensions: new knowledge, further application, bad impression and good impression.

\section{Objective}

The aims of this study were to develop the scholarly English oral presentation ability of the pre-service teachers majoring in English, studying at Faculty of Education, Suan Sunandha Rajabhat University, using Miller's model and to investigate their attitudes towards teaching based on this model.

\section{Scope of the Study}

1. The sampling group of this study was 26 English major pre-service teachers enrolling in English for Academic Purposes in 2015, Faculty of Education, Suan Sunandha Rajabhat University.

2. The course which was a part of this study is English for Academic Purposes. This is a compulsory course for 4th year pre-service teachers majoring in English.

3. The independent variable was Miller's model-based instruction and the dependent variable was scholarly English presentation ability.

4. The time frame of this study began from January 2015 to April 2015.

\section{RELATED LITERATURE}

In the general situations where English communication takes place, the speaking problems can occur regularly in several ways as follows: 1 ) a speaker makes fluent but inaccurate speech, 2) a speaker makes grammatically correct but not fluent speech, 3) a speaker can communicate correctly and fluently but only within limited situations and 4) a speaker can communicate effectively in various situations but still has problems with stressing and intonation (Adhikari, 2010; Thornbury, 1999). Al-Hosni (2014) and Plailek (2011) informed that, in the word level, jerky speaking and pronunciation errors still exist among those who are not native speakers of English and even individuals with strong English knowledge still commit these problems in case there are some unfamiliar words. In the sentential level, Gan (2012) and Unnanantn (2006) stated that the use of English in Thai structure frequently occurs and there are embedded errors in word use which are derived from word for word translation. Besides, another problem of those with limited speaking skill is that they are unable to construct and, as a result, express sentences in a comprehensive way. Therefore, when they are to speak, they always say separate words. Thought they can speak with accurate grammar, they cannot make use of it to arrange their ideas in a logical and meaningful way (Alyan, 2013). From these problems, Brown, (1980) and Parker and Kathryn (1994) proposed that the intrinsic difficulty of a target language and 
the differences between a target language and a native language are the considerable factors affecting the speaking skill development and so does a learning environment. Juhana (2012), CheeKeong et al. (2014), Pongpanich (2011) and Ritthirat (2014) added that shyness, fear of mistakes and having limited word bank are obstacles to speaking improvement and these also cause an attitude that English is difficult to master. Regarding instructional factors, if teachers use their own mother tongue instead of English every time, their students will not assimilate adequate uses of the target language and have no opportunity to try using expressions they have learnt. In a similar circumstance, rehearsing textbook expressions makes them familiar with an only direct and bookish language which cannot help them use the language appropriately and artistically in different situations, Cameron (as cited in Al-Hosni, 2014). In a more complicated level of speaking or in an academic presentation, Sukitkanaporn and Supakorn (2014) proposed that the problems are delivery, information organization, unclear opening and reading through screen for the presenter side. Besides, inadequate speaking skill and worry about content of presentation can affect the fluency of a presenter Radzuan and Kaur (cited in Yeereem, 2013) and so can the first language interference and some unfamiliar genres which belong to the linguistic aspect (Yeereem, 2013).

Although teaching vocabulary and grammar for a communicative purpose is an important preliminary principle for English speaking development, the arts of public speaking should be simultaneously taught to prepare the students for situational speaking. Since only excellent knowledge on the language, itself, is not enough, the students should be grounded in the techniques of making their speech powerful and impressive. Chaiyapan (2012) proposed that the principles of situational speech arts need to be taught step by step for effective speaking in accordance to several contexts and mannerly matters in which there are structural greetings, introduction, information organization plus linking, conclusion and finishing. Also, all of these components need to be flawlessly and smoothly spoken with a good language use and word selection, clarity, cross-cultural awareness, cultural knowledge Alvesson; Gupta and Govindarajan; Holden; Leonard and Sensiper (cited in Sukitkanaporn and Supakorn, 2014), correct background support, completeness and orderly organization. For the content organization, it can be arranged from general to specific matters, problems to solutions and causes to effects Grand; Storz; Williams (as cited in Yeereem, 2013). For greater success, the relevance to an audience's expectation (Yeereem, 2013), the well-trained use of gestures and social manners are inseparable qualities of being a good public speaker because these, together, form the stereotype listeners always depend on to judge whether a speaker presents or does the delivery of speech naturally and convincingly or not.

From the problems, the related factors and the awareness about the oral presentation ability in public or formal situations, the development of this quality is a greater challenge for English instructors as it needs patience, consumes much time and can be succeeded through regular practices until the students can perform naturally and professionally. From several teaching methods for skill and knowledge development, Miller's model is a procedural teaching approach originated from skill and knowledge improvement for medical students and accompanied by formative assessment; therefore, the implementation of this model needs to follow the 4 sequential procedures as Miller (1990) created.

1. Knows: The instruction at this stage is to give knowledge, principles or theories as basis to students. Also, the assessment will be conducted to prove their recognition.

2. Knows how: At this stage of instruction, students are given opportunities to explain or analyze the subject matter that they have learnt. The assessment will prove how well they 
understand through analyses, exemplification and application outlooks, for example.

3. Shows how: The students are assigned to demonstrate their learnt knowledge or skills by themselves in a controlled environment or a classroom atmosphere.

4. Does: The students are given an opportunity to use their knowledge and skills from the lessons in a real context to solve a problem or case study, make new creations or work in a workplace without any helping hand and immediate correction of their teacher anymore.

In regard of this approach, Rethans et al. (2002) emphasized that instruction in a simulated context with a teacher's assistance to nurture and practice all the time is not enough for making learning experience grow up and strong at an ample level for implementation in real life. Therefore, the connection between class learning and real situations needs to be made so that students can learn more from their hands-on attempts to overcome interventions knowingly and, sometimes, cope with some uncontrollable states smartly to perform successfully in authentic situations. In spite of depression, the experiential learning can help them mature, extend their views due to more hands-on experiences, and enhance their competence strengths.

Along all the stages of teaching, the assessment cannot be excluded or conducted optionally. In the model's design, the assessment begins at the Knows stage to test what and how much the students have learnt. Next, in Knows how, the aim of assessment is to test whether the students are able to explain, analyze or illustrate a clear picture of further implementation of the knowledge or not. In a higher level, Shows how, Rethans et al. (2002), Boursicot et al. (2011) and Ruedy (2007) presented the students' demonstration or task accomplishments in a controlled context are assessed to prove which degree their competence belongs to. Beyond their competence, their performance in the real world is also assessed in the final stage, Does, and the assessment covers broader criteria.

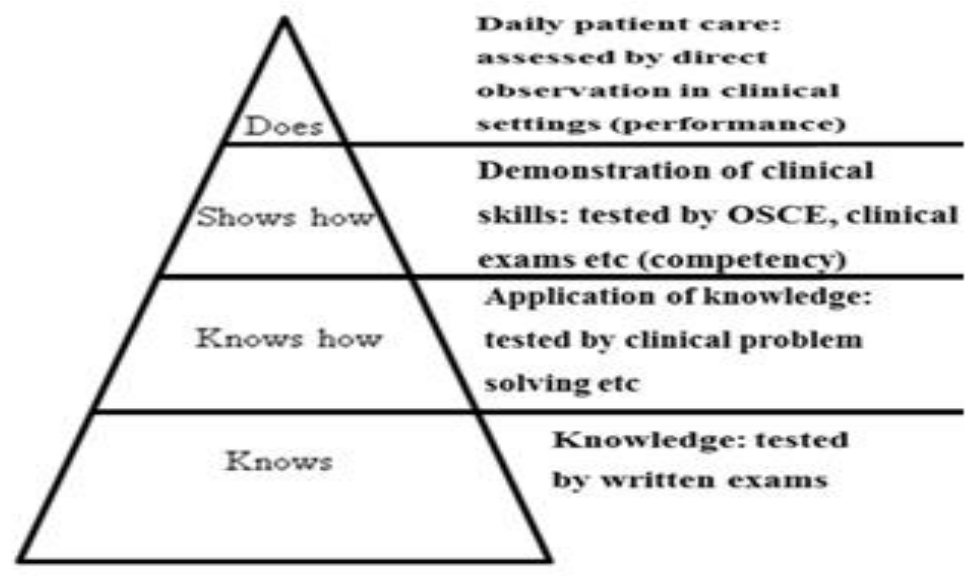

FIGURE 1. The adapted framework of instruction and assessment of Miller's model, Adapted from Miller (1990)

Source: Ramani and Sam (2008)

From the above model which logically combines both teacher-controlled and experiential methods, teaching academic English presentation which requires more formality and carefulness than ordinary conversations should be in an orderly condition from principle grounding to real performance. For the utmost effectiveness and rewarding outcomes, formative assessment is settled as a part of each instructional stage for the reason of close progress check and nurture so that misunderstandings or difficulties occurring 
while learning can be solved and corrected immediately. Otherwise, they will appear repeatedly and, eventually, fossilized. In regard of pedagogy, either using hands-on practices or merely giving lectures cannot fulfill the need to make the students reach a high standard of quality. So, both deductive and inductive instruction can be combined and systematized within the structure of the model in which there are cognition (Knows and Knows how) and 2 levels of behavior: competence (Shows how) and performance (Does). However, Anderson (2004) presented that, based on the learning pyramid by Dale, running participatory activities can be greatly of better contribution to higher learning achievements and retention than adopting only the auditory approach which has the lowest supportive potential. In this study, the researcher realized that giving lectures as an auditory approach is still a crucial method to explain correct knowledge, principles, theories and concepts to students in both class and face-to-face basis so that they can possess accurate and necessary basics for doing better in other experiential and kinesthetic learning activities. Essentially, lecture-based teaching can be used as a remedial option to solve the students' risk to develop misconception and wrong assumption in case some activities fail to develop them in a meaningful way. Therefore, the researcher included giving lectures as part of the development process in Miller's model.

\section{INSTRUMENTS AND METHODOLOGY}

The research focused on academic English presentation development and the methodology is as follows:

\section{Planning and Instrument Design}

1. The researcher reviewed theories, principles, research studies, and scholarly work on oral presentation development and Miller's model.

2. The researcher reviewed the course content and its objectives. Then, the drafts of a course syllabus, scholarly presentation and language tests and scholarly presentation assessment forms were written and all of these accorded with Miller's model. An attitude questionnaire was also created.

3 . The researcher submitted all the research instruments to 3 experts for close consideration. After the process, the IOC of the instruments was .66-1.00.

4. The researcher edited the instruments as advised by the experts.

\section{Data Collection}

The researcher taught the students by following Miller's model and its process starting from Knows, Knows how, Shows how and Does. At the end of this course, the attitude investigation began. Hence, the details of data collection were divided into 2 parts as follows:

1. Instrument

1.1 Knows

- The rules and use of English for presentation, information systematization, non-verbal language awareness and successful presentation techniques were taught through the combination of lecture, brainstorming, discussion and rotation.

- After the activities, they were assigned to summarize their knowledge and understanding individually.

- Each of them took a scholarly presentation knowledge and language test.

1.2 Knows how

- The combination of lecture, brainstorming, discussion and rotation was implemented for 
teaching the use of relevant language expressions, the information structure and systematization and appropriate communication strategies.

- For the individual task, they were assigned to apply the knowledge to draft a presentation manuscript.

- Each of the students was tested with the other set of scholarly presentation knowledge and language test which was more on analysis and application.

1.3. Shows how

- The students did their individual presentation rehearsal of their selected topics under the theme of English teaching in front of the class and the classmates asked, shared ideas, and commented.

- The researcher assessed their presentation abilities with an assessment form on simulated presentations and suggested techniques to practice.

1.4. Does

- The researcher was in a cooperation to hold a symposium to encourage the students to do their individual academic presentations in English, and the participants were from different majors, faculties and institutes.

- The students' presentation abilities were assessed with an authentic performance assessment form by the invited native English lecturers from other institutes.

2. Attitude Investigation

- At the end of the symposium, the attitudes towards the teaching methodology based on Miller's model were investigated. The 4 dimensions of topical questions on new knowledge, further application, good impression, and bad impression comprised of an openended questionnaire for this study.

\section{FINDINGS}

The results of the development are shown in the Table 1. For the development from Knows to Knows how, 16 undergraduates had improvement by $10 \%-20 \%$ and the score of the other 10 was unchanged.

In the linkage between Knows how and Shows how, 8 of them made an increase by $10 \%-20 \%$ and 8 students did not make any changes. However, 10 students made a decrease by $10 \%-30 \%$.

For the continuity between Shows how and Does, the number of 14 English major students made a rise by $2 \%-28 \%$ and 5 had the stable score. Nevertheless, the scores of 7 students marginally fell by $2 \%-8 \%$.

From all of the development stages, the mean score of 16 students was $82 \%-95 \%$ and rated in the very good degree. For the others, theirs were ranged from $73.5 \%-81 \%$ which belonged to the good degree.

From the above table, all the written opinions by the students were analyzed and grouped in each dimension. In the first dimension, the majority of the students or $76.92 \%$ gained knowledge on communication strategies, a variety of expressions for powerful presentation and innovation in English teaching presented in several reading materials. 50\% of them had better understanding on the appropriate use of words in scholarly work.

For their voices on further implementation, $80.77 \%$ of them would adopt the learning activities, the teaching methodology used in this study and the knowledge from readings to teach their future school students. Besides, $69.23 \%$ said that information structuring and the language use in terms of paraphrasing and academic language style were useful for their teaching profession in the future. In addition, $61.54 \%$ stated the presentation techniques were useful to help them overcome stage fright and enhance their confidence. In the part of impression, no one was left behind due to the extra-time support by the 
researcher and the whole class enjoyed the activities and viewed the symposium as an opportunity to evaluate their language ability, share and learn from others rather than feeling depressed. Importantly, $80.77 \%$ of them mentioned that feedback among peers helped them learn and made them more active listeners. As a result, no bad attitude appeared.

TABLE 1 . The percentage comparison of consecutive and mean score results of scholarly English presentation ability development

\begin{tabular}{llllll}
\hline \hline Students & Knows (\%) & Knows how (\%) & Shows how (\%) & Does (\%) & Mean (\%) \\
\hline 1 & 70 & 80 & 80 & 80 & 77.5 \\
2 & 80 & 80 & 90 & 100 & 87.5 \\
3 & 90 & 90 & 80 & 98 & 89.5 \\
4 & 70 & 80 & 80 & 94 & 81 \\
5 & 80 & 90 & 100 & 94 & 91 \\
6 & 90 & 90 & 80 & 92 & 88 \\
7 & 90 & 90 & 60 & 88 & 82 \\
8 & 60 & 80 & 90 & 86 & 79 \\
9 & 70 & 80 & 80 & 88 & 79.5 \\
10 & 70 & 90 & 90 & 84 & 83.5 \\
11 & 90 & 90 & 80 & 88 & 87 \\
12 & 90 & 90 & 100 & 100 & 95 \\
13 & 80 & 80 & 80 & 72 & 78 \\
14 & 70 & 80 & 80 & 92 & 80.5 \\
15 & 90 & 90 & 80 & 80 & 85 \\
16 & 70 & 90 & 100 & 94 & 88.5 \\
17 & 70 & 90 & 80 & 100 & 85 \\
18 & 60 & 70 & 90 & 92 & 78 \\
19 & 70 & 80 & 90 & 96 & 84 \\
20 & 70 & 90 & 80 & 80 & 80 \\
21 & 70 & 90 & 60 & 74 & 73.5 \\
22 & 90 & 90 & 60 & 88 & 82 \\
23 & 70 & 90 & 90 & 88 & 84.5 \\
24 & 70 & 80 & 80 & 88 & 79.5 \\
25 & 90 & 90 & 80 & 80 & 85 \\
26 & 70 & 90 & 100 & 94 & 88.5 \\
Mean (\%) & 76.53 & 85.76 & 83.07 & & 83.55 \\
\hline
\end{tabular}

\section{CONCLUSION AND DISCUSSION}

1. According to the score results of the students after the development with Miller's model which consists of Knows, Knows how, Shows how and Does stages, the researcher found that the students' knowledge in the first stage was rated from the average to the very good levels. The reasons for the case of those whose results were in the average level may have been because of their insufficient background of English structures. Alyan (2013) and Gan (2012) supported that the interference of Thai to their English usage, anxiety on English grammar and word-for-word translation can result to errors and communication breakdown. Therefore, the extra help, a small group lecture, was provided to them. However, that some were able to score in the good and the very good levels may have been resulted from the activities, extended from the class lectures, with a meaningful emphasis on knowledge sharing, learning by doing and self-correction. This can be supported by the academic work on the learning pyramid by Dale that a kinesthetic class activity 
TABLE 2. The pre-service teachers' attitudes towards Miller's model-based instruction for scholarly English presentation ability development

\begin{tabular}{llll}
\hline \hline Dimensions of Questions & Feedback List & Students (N = 26) & Percentage \\
\hline New Knowledge & -Art of communication & 20 & 76.92 \\
& -Knowledge from reading and information retrieval & 20 & 76.92 \\
& -Difference between academic words and general word & 13 & 50 \\
\hline Further Application & -The teaching method & 21 & 80.77 \\
& -Knowledge from reading and information retrieval & 21 & 80.77 \\
& -Language use & 18 & 69.23 \\
& -Information structuring & 21 & 69.23 \\
& -Presentation techniques & 16 & 61.54 \\
\hline Good Impression & -Teacher's assistance & 26 & 100 \\
& -Learning activities & 26 & 100 \\
& -Peer feedback activity & 12 & 80.77 \\
\hline Bad Impression & N/A & N/A & N/A \\
\hline \hline
\end{tabular}

which includes discussion, hands-on practices and teaching or sharing knowledge to others can promote elaboration, memory retention and, consequently, self-improvement on knowledge and skills (Anderson, 2004). For Knows how, their score rated in the good and the very good levels represented that they possessed clear understanding, analysis and application of the taught knowledge. This was a phenomenon telling that giving the extratime advisory support plus lectures and more of opportunities for individual practices was very encouraging for those who were anxious and lacked confidence while learning in class. Doing so helped increase self-improvement motivation, made English learning stress-free and kept them in the right track of practice. Morrow and Keith (1981) and Littlewood (1981) also supported that the more supportive and less depressing learning environment can be made by making learners free of stress and avoiding too often correction. After both of the cognitive stages, the competence development, Shows how, was conducted to have them demonstrate their learnt knowledge in a simulated environment controlled by the researcher. From their mocked-up scholarly presentations, the minority's ability was in the average level. This was because of difficulties in speech sound production, information organization and stage fright while in front of the class. This was agreed by Al-Hosni (2014) in that the confusion among some English words with more than one pronunciation pattern and accidentally facing some unfamiliar words caused learners' speaking problems. Besides, the inability to systematically arrange ideas made presentation incomprehensible (Alyan, 2013). Juhana (2012), CheeKeong et al. (2014), Pongpanich (2011) and Ritthirat (2014) added that shyness, fear of mistakes, insufficient word bank and low self-esteem can result in the diffidence which can be noticed through speech act and non-verbal clues. To make improvement, an individual practice session by appointment was scheduled for them. Meanwhile, many could reach the good and the very good levels. The factor contributing to their progress may have been the endurable understanding on principles nurtured from the mix of lectures, extra support and a more proportion of activities used in Knows and Knows how. This can be illustrated that participatory activities can yield learners an outlook to the further use of knowledge, hone them for better performance and learning and implement their knowledge logically (Morrow, and Keith, 1981; Littlewood, 1981).

In the Does stage where the symposium was held, the students were able to do their En- 
glish presentations and perform in the good and very good degrees because of advantages of the rehearsal in which questions and comments by their classmates helped them learn more from mistakes, pointed out information gaps to fulfill and gave a reflection of their speech delivery and credibility in front of public. As for the audience, learning from the environment rich in feedback sharing was their passive experience for improving their preparation. That is, to enable any skill of learners, the process of honing for improvement must be made integrative to application in the real world and this articulation must be based on experiential learning for endurable skills and knowledge.

Furthermore, the perception of success, feedback and advice in each developmental stage can be of scaffolding to greater motivation of self-development (Panich, 2013; Rethans et al., 2002).

2. From the rewarding results of the attitude investigation, the nurture with understanding on the pre-service teachers' different levels of ability and prior knowledge and the energizing and supportive learning environment were able to generate positive attitudes which lead to the increase of motivation to delve deep into the knowledge and devote to self-development in both theoretical and practical sides. For this reason, motivation also played an important role in learning success. To this point, Brown (2007) and Harmer (1991) emphasized that learners with high motivation, self-esteem and low level of anxiety can be more successful in learning and perform better in many assigned tasks though there may be some difficulties, depression and several times of correction. Besides the view on learners, positive attitudes can yield a reflection on teaching effectiveness and both direct and indirect factors of success. As a consequence, the attitudes qualify valuable information for instruction, material and learning atmosphere improvement direction (Ciobanu and Livia, 2014; Emanuel and Adams, 2006; Guilloteaux and Zoltán, 2008; Paulins, 2005).

\section{CONCLUSION}

Following conclusion can be drawn for this study.

1. As Miller's model involves both cognitive and behavioral levels of instruction and is open for arranging and combining several teaching approaches and techniques in each stages, any activities and types of learning, for example, self-regulated learning, blended learning and e-learning, are allowed to bring in.

2. The assessment along Miller's model is recommended to use on an individual basis to analyze students' different progress and weaknesses rather than a team basis because its emphasis is to develop individuals to work or perform wisely and effectively in an independent condition.

3. A small class size is an appropriate circumstance to put this model into practice because providing support to help all students can be done individually with greater effectiveness and efficiency when compared to doing so in a very large class size.

4. In addition to teaching a course in a university class context, this model can be used as part of curriculum or training development in which on-the-task performance is sequenced as the ultimate goal or outcomes learners are required to achieve and perform independently.

\section{LIMITATIONS AND RECOMMENDATIONS}

1. Because the use of Miller's model worked greatly on the ability leverage through deductive to inductive stages, learning strategies and behaviors that students used to progress through each step should be investigated. 
2. For greater knowledge extension, a comparison between Miller's model implementation and the use of other instruction model should be conducted.

3. A research study attempting to make integration between Miller's model and other model to form a creation for some particular skill development can be a good contribution to the academic milieu.

\section{ACKNOWLEDGEMENT}

This research was successfully accomplished mainly because of the great support by Suan Sunandha Rajabhat University (SSRU), Institute of Research and Development, SSRU, and Dean of Faculty of Education, SSRU. I also would like to express my gratitude to Dr. Suttipong Boonphadung, Vice Dean for Research and Academic Service, SSRU, Ms. Teeraporn Plailek, Lecturer of English, SSRU, and Ms. Ratchanee Jamsai, Lecturer of English, Sripatum University, for giving useful advice and Mrs. Abigail Melad Essien, Lecturer of English, SSRU, for additional assistance. In addition, I would like to place my sincere thanks to my family and Ms. Pattamawan Supasri for encouragement.

\section{REFERENCES}

Abdul Amir, Abdul Rahman Z. 2015. Utilization of request mitigators by Omani learners of English and native speakers: A comparative study. International Journal of Humanities, Arts and Social Sciences 1, no. 4: 156-172.

DOI: $10.20469 /$ ijhss.20004-4

Adhikari, Bal Ram. 2010. Teaching speaking in the Nepalese context: Problems and ways of overcoming them. Journal of NELTA 15, no. 1-2: 1-9.

Allery, Lynne. 2009. How to teach practical skills. Education for Primary Care 20, no. 1: 58-60.

DOI: $10.1080 / 14739879.2009 .11493762$

Al-Hosni, Samira. 2014. Speaking difficulties encountered by young EFL learners. International Journal on Studies in En- $\quad$ glish Language and Literature 2, no. 6: 22-30.

Al-Wardy, Nadia M. 2010. Assessment methods in undergraduate medical education. Sultan Qaboos University Medical Journal 10, no. 2: 203-209.

Alyan, Abedrabu A. 2013. Oral communication problems encountering English major students: Perspectives of learners and teachers in Palestinian EFL University context. Arab World English Journal 4, no. 3: 226-238.

Anderson, Heidi M. 2004. Dale's Cone of experience. URL: goo.gl/qKjHdt (accessed June 20, 2013).

Angwatanakul S. 1994. English teaching methods. 2nd ed. Bangkok: Chulalongkorn University Press.

Boonphadung, Suttipong and Thassanant Unnanantn. 2015. Miller's model for developing critical thinking skill of pre- service teachers at Suan Sunandha Rajabhat University. International Journal of Social, Education, Economics and Management Engineering 9, no. 2: 561-566.

Boursicot, Katharine, Luci Etheridge, Zeryab Setna, Alison Sturrock, Jean Ker, Sydney Smee and Elango Sambandam. 2011.

Performance in assessment: Consensus statement and recommendations from Ottawa conference. Medical Teacher 33: $\quad 370-383$.

Brown, H. Douglas. 2007. Teaching by principles: An interactive approach to language and pedagogy. New York, NY: Pearson Publishing.

Brown, H. Douglas. 1980. Principles of language learning and teaching. New Jersey, NJ: Prentice Hall.

Chaiyapan S. 2012. Theory of communicate with people in society. Princess of Naradhiwas University Journal 4, no. 3: 140-154.

Ciobanu, Alina, and Livia Ostafe. 2014. Student satisfaction and its implications in the process of teaching. Acta Didactica Napocensia 7, no. 4: 31-36.

Emanuel, Richard, and Adams JN. 2006. Assessing college student perceptions of instructor customer service via the Quality of Instructor Service to Students (QISS) questionnaire. Assessment \& Evaluation in Higher Education 31. no. 5: ISSN: 2414-3111 


\section{5- 549. DOI: $10.1080 / 02602930600679548$}

Foddy, William. 1993. Constructing questions for interviews and questionnaires: Theory and practice in social research. Cambridge, UK: Cambridge University Press. DOI: 10.1017/CB09780511518201

Gan, Zhengdong. 2012. Understanding L2 speaking problems: Implications for ESL curriculum development in a teacher training institution in Hong Kong. Australian Journal of Teacher Education 37, no. 1: 42-59.

DOI: $10.14221 /$ ajte.2012v37n1.4

Guilloteaux, Marie J., and Zoltán Dörnyei. 2008. Motivating language learners: A classroom oriented investigation of the effects of motivational strategies on student motivation. TESOL Quarterly 42, no. 1: 55-77.

DOI: $10.1002 / \mathrm{j} .1545-7249.2008 . t b 00207 . x$

Harmer, Jeremy. 1991. The practice of English language teaching-Motivational differences. London, UK: Longman.

Juhana, Juhana. 2012. Phychological factors that hinder students from speaking in English class (A class study in a senior high school in South Tangerang, Banten, Indonesia). Journal of Education and Practice 3, no. 12: 100-110.

Plailek, Teeraporn. 2011. Factors effecting English speaking ability of second year English major students in the faculty of education, Rajabhat Universities in Bangkok Metropolitan area. Research and Development Journal 3, no. 1: 52-58.

Morrow, Keith, and Keith Johnson. 1981. Communication in the classroom. London, UK: Longman.

CheeKeong, Yuen, AmrAbdullatif Abdullah Y., and Ta ha Talib A A. 2014. Oral communication problems of Yemeni high school EFL students in Malaysia. Journal of Applied Sciences 14, no. 24: 3620-3626. DOI: 10.3923/jas.2014.3620.3626

Littlewood, William. 1981. Communicative language teaching. New York, NY: Cambridge University Press.

Miller, George E. 1990. The assessment of clinical skills/ competence/ performance. Academic Medicine 65, no. 9: S63-S67.

Norcini, John J. 2003. Work-based assessment. British Medical Journal 326, no. 7392: 753-755.

DOI: $10.1097 / 00001888-199009000-00045$

Oradee, Thanyalak. 2012. Developing speaking skills using three communicative activities (Discussion, problem-solving, and role-playing). International Journal of Social Science and Humanity 2, no. 6: 533-535.

Panich V. 2013. How does learning occur? URL: goo.gl/j89vbm (accessed May 1, 2015).

Parker, Frank, and Kathryn Louise R. 1994. Linguistics for non-linguists. 2nd ed. Boston, MA: Allyn and Bacon.

Paulins, V. Ann. 2005. An analysis of customer service quality to college students as influenced by customer appearance through dress during the in-store shopping process. Journal of Retaining and Consumer Services 12, no. 5: 345-355. DOI: $10.1016 / j$.jretconser.2004.11.003

Pongpanich, Nongsamorn. 2011. A study of problems in English speaking in speech communication of management sciences students, Kasetsart University, Sriracha Campus: October 2007 to September 2008. Humanities Journal 18, no. 1: 85-97.

Ramani, Subha, and Sam Leinster. 2008. Teaching in the clinical environment. Medical Teacher 30, no. 4: 347-364.

Rethans, JJ., Norcini JJ., Baron-Maldonado M., Blackmore D., Jolly BC., LaDuca T., ... \& Southgate, LH. 2002. The relationship between competence and performance: Implications for assessing practice performance. Medical Education 36, no. 10: 901-909.

Ritthirat, N. 2014. Thai university student's English oral proficiency and problems to developing English speaking skill. Master's thesis. URL: http://kb.psu.ac.th (accessed May 1, 2015).

Ruedy, John. 2007. Assessing students-Clinical competence versus performance. International e-Journal of Science, Medicine \& Education 1, no. 1: 15-21.

Sukitkanaporn, Thitibhada, and Supakorn Phoocharoensil. 2014. English presentation skills of Thai graduate students. English Language Teaching 7, no. 3: 91-102.

Taher, Md. Abu, Prithvi N. Shrestha, Md. Mizanur Rahman, A.K.M Iftekhar Khalid. 2016. Curriculum Linked Video (CLV) as a tool for English Language Teaching (ELT) at secondary school classrooms in Bangladesh. International Journal of Humanities, Arts and Social Sciences 2, no. 4: 126-132. DOI: 10.20469/ijhss.2.20002-4

Tantrakul, T. 2014. Development of speaking skills for everyday life using conversation exercises.

URL: https://goo.gl/9WrpXB (accessed May 1, 2015).

Thornbury, Scott. 1999. How to teach grammar. London, UK: Pearson Education Limited.

Unnanantn, P. 2006. An analysis of syntactic errors: a case study in business report writing, Master's Project. URL: 
http://tdc.thailis.or.th (accessed March 16, 2017).

Ye ereem, Cherdask. 2013. A comparative study of language use in oral presentations of Thai ESL learners and englishnative students. Master's thesis, Prince of Songkla University, Kho Hong, TH.

— This article does not have any appendix. - 